\title{
Dificuldades de prevenção ao vírus HIV na população jovem e a importância da
}

\section{prevenção combinada}

\author{
HIV virus prevention difficulties in the young population and the importance of combined \\ prevention
}

Dificultades en la prevención del virus del VIH en la población joven y la importancia de la prevención combinada

Geysa Dianne Figueiredo Lima ORCID: https://orcid.org/0000-0002-5934-4428 Faculdade Integrada Carajás, Brasil E-mail: geysa182010@ hotmail.com

Marcos Vinícios Ferreira dos Santos ORCID: https://orcid.org/0000-0003-1335-1021 Faculdade Integrada Carajás, Brasil

E-mail: viniciosferreirasantos@hotmail.com

\begin{abstract}
Resumo
Por décadas, a infecção pelo HIV, acomete pessoas por toda parte do mundo, independentemente da classe social, sexo, orientação sexual, cultura ou idade. Mais da metade dos novos casos registrados de infecções por HIV que ocorrem na atualidade afetam jovens de 15 a 24 anos de idade. Para guiar essa presente revisão bibliográfica, elaborou-se o seguinte questionamento: $\mathrm{Na}$ literatura analisada, quais as principais dificuldades enfrentadas no tocante a prevenção da infecção pelo vírus HIV na população jovem brasileira? E o objetivo foi identificar os fatores contribuintes que dificultam a prevenção ao vírus HIV na população jovem no Brasil e os meios utilizados para abordagem desse grupo. Para alcance do objetivo da pesquisa optou-se pelo delineamento de uma pesquisa bibliográfica narrativa, utilizando-se os artigos de língua portuguesa, que abrangessem o tema abordado, disponíveis nas bases de dados na íntegra, publicados no período compreendido entre 2011 a 2021 . Observou-se que a maiores dificuldades de prevenção vírus HIV na população jovem está relacionada as vulnerabilidades que este grupo está exposta. Já as práticas educativas, todas as apresentadas na revisão se mostraram eficientes, uma vez que métodos inovadores, buscando chamar a atenção do público alvo foram bem aceitos e obtiveram participação ativa dos envolvidos. Por fim, foi possível observar, que a maior parte das produções publicadas no recorte temporal proposto por esta revisão, estão voltadas a apresentar as vulnerabilidades do público jovem ao HIV, e que destacam a importância das políticas públicas mais centradas nesse público.
\end{abstract}

Palavras-chave: HIV/AIDS; Prevenção; Jovens; Vulnerabilidade; Prevenção combinada.

\begin{abstract}
For decades, HIV infection has affected people all over the world, regardless of social class, gender, sexual orientation, culture or age. More than half of the new reported cases of HIV infections that occur today affect young people aged 15 to 24 years. To guide this literature review, the following question was elaborated: In the literature analyzed, what are the main difficulties faced with regard to the prevention of HIV infection in the young Brazilian population? And the objective was to identify the contributing factors that hinder the prevention of the HIV virus in the young population in Brazil and the means used to approach this group. To achieve the research objective, we opted for the design of a narrative bibliographic research, using articles in Portuguese, covering the topic, available in full databases, published in the period from 2011 to 2021. It should be noted that the greatest difficulties in preventing the HIV virus in the young population are related to the vulnerabilities that this group is exposed to. As for the educational practices, all those presented in the review proved to be efficient, since innovative methods, seeking to draw the attention of the target audience, were well accepted and had the active participation of those involved. Finally, it was possible to observe that most of the productions published in the time frame proposed by this review are aimed at presenting the vulnerabilities of the young public to HIV, and that they highlight the importance of public policies more focused on this public.
\end{abstract}

Keywords: HIV/AIDS; Prevention; Young; Vulnerability; Combined prevention. 


\begin{abstract}
Resumen
Durante décadas, la infección por el VIH ha afectado a personas de todo el mundo, independientemente de su clase social, género, orientación sexual, cultura o edad. Más de la mitad de los nuevos casos notificados de infecciones por el VIH que se producen en la actualidad afectan a jóvenes de entre 15 y 24 años. Para orientar esta revisión de la literatura, se elaboró la siguiente pregunta: En la literatura analizada, ¿cuáles son las principales dificultades enfrentadas con respecto a la prevención de la infección por VIH en la población joven brasileña? Y el objetivo fue identificar los factores contribuyentes que dificultan la prevención del virus del VIH en la población joven de Brasil y los medios utilizados para abordar este grupo. Para lograr el objetivo de la investigación, se optó por el diseño de una investigación bibliográfica narrativa, utilizando artículos en portugués, que cubran el tema, disponibles en bases de datos completas, publicados en el período 2011 a 2021. Cabe señalar que las mayores dificultades en la prevención el virus del VIH en la población joven está relacionado con las vulnerabilidades a las que está expuesto este grupo. En cuanto a las prácticas educativas, todas las presentadas en la revisión demostraron ser eficientes, ya que los métodos innovadores, que buscan llamar la atención del público objetivo, fueron bien aceptados y contaron con la participación activa de los involucrados. Finalmente, se pudo observar que la mayoría de las producciones publicadas en el marco temporal propuesto por esta revisión tienen como objetivo presentar las vulnerabilidades del público joven al VIH, y que resaltan la importancia de políticas públicas más enfocadas a este público.
\end{abstract}

Palabras clave: VIH/SIDA; Prevención; Joven; Vulnerabilidad; Prevención combinada.

\title{
1. Introdução
}

O Vírus da Imunodeficiência Humana (HIV), é o responsável por causar a Síndrome da Imunodeficiência Adquirida (Aids). Esta é uma doença crônica, de caráter emergente. O vírus tem capacidade de atacar o sistema imunológico do hospedeiro, deixando-o susceptível a novas infecções (Cordeiro et al., 2017).

Emergiu como uma epidemia no final da década de 70, passando a ser um dos mais graves problemas da saúde pública no mundo. Os primeiros casos foram detectados nos Estados Unidos, Haiti e a África Central (Dartora, Ânflor \& Silveira, 2017). No Brasil a epidemia se deu em 1980, concentrando-se na região Sudeste, com 465 mil casos registrados pelo Ministério da Saúde (MS). A população acometida era composta por homossexuais; posteriormente, usuários de drogas injetáveis, hemotransfundidos, mulheres, crianças e idosos (Cordeiro et al., 2017).

Por décadas, a infecção pelo HIV, acomete pessoas por toda parte do mundo, independentemente da classe social, sexo, orientação sexual, cultura ou idade. Desde que foi descoberto até os dias de hoje, diversas iniciativas por parte dos governos, profissionais da saúde e da educação foram realizadas objetivando a promoção de ações educativas para a população acerca do modo de transmissão do vírus, prevenção e tratamento. Por meio destas, também visam diminuir o estigma e preconceito que a doença acarreta. Devido a estas ações, nos últimos anos ocorreu a estagnação de novos casos de HIV no mundo, no entanto, no Brasil, os casos entre jovens tenderam a aumentar (Monteiro et al., 2019).

No Brasil, em 2019, foram diagnosticados 41.909 novos casos de HIV e 37.308 casos de aids - notificados no Sistema de Informação de Agravos de Notificação - SINAN, declarados no Sistema de Informações de Mortalidade - SIM e registrados no Sistema de Controle de Exames Laboratoriais - SISCEL e Sistema de Controle Logístico de Medicamentos - SICLOM, com uma taxa de detecção de 17,8/100 mil habitantes, totalizando, no período de 1980 a junho de 2020, 1.011 .617 casos de aids detectados no país (Brasil,2020).

De acordo com Dartora, Anflor e Silveira (2017), dos países da América Latina, o Brasil é o que mais concentra casos novos de infecções pelo vírus HIV, correspondendo a $40 \%$ destas. A proporção de detecção de casos de AIDS entre os anos de 2006 a 2016, entre jovens do sexo masculino com idade de 15 a 19 anos triplicou de 2,4 para 6,7 casos por 100 mil habitantes. Já na faixa etária dos jovens com idade de 20 a 24 anos, a taxa multiplicou de 15,9 para 33,9 casos por 100 mil habitantes (Monteiro et al., 2019).

Dados apresentados pelo Ministério da Saúde atestam que mais de 70\% dos casos de Síndrome da Imunodeficiência Adquirida (AIDS) correspondem a indivíduos entre 20 e 39 anos, visto que uma parte considerável desses pacientes contraiu o vírus na adolescência (Brasil, 2017). Associa-se esse fato, a condição de que essa faixa etária se encontra no período 
reprodutivo humano, no qual as pessoas são sexualmente mais ativas e com possibilidade de terem múltiplos parceiros (Oliveira et al., 2013). E a relação sexual é apontada como sendo o principal meio de contaminação entre os jovens maiores de 13 anos, tanto em homens (92,9\%) quanto em mulheres (82,2\%) (Vilares, Casseb, Gascon, \& Fonseca, 2018).

Existem políticas públicas que asseguram o acesso universal ao tratamento, ao preservativo, ao teste e, por conseguinte, à chamada "prevenção combinada" no Sistema Único de Saúde (SUS). Mesmo assim, ainda acumulamos por volta de 40.000 novos casos de Aids por ano, dado preocupante entre os jovens, homens, e pessoas vivendo nos grandes centros urbanos (Paiva; Antunes \& Sanches, 2020).

Frente ao exposto o presente estudo se justifica devido a observação dos inúmeros desafios enfrentados para se fazer a prevenção, conscientização e entendimento sobre HIV/aids na população jovem. O vírus HIV circula no Brasil a aproximadamente 41 anos mesmo com tantas pesquisas e avanços sobre, ainda não se consegue uma adesão suficiente de prevenção, diagnóstico e tratamento.

Para guiar essa presente revisão bibliográfica, elaborou-se o seguinte questionamento: Na literatura analisada, quais as principais dificuldades enfrentadas no tocante a prevenção da infecção pelo vírus HIV na população jovem brasileira?

\section{Metodologia}

Para alcance do objetivo da pesquisa optou-se pelo delineamento de uma pesquisa bibliográfica narrativa. Os artigos de revisão narrativa são publicações desenvolvidas para descrever e discutir o desenvolvimento ou o 'estado da arte' de um assunto definido, sob ponto de vista teórico ou conceitual (Costa, Mota, Paiva \& Ronzani, 2015). Esse tipo de pesquisa possui grade relevância, por permitir ao leitor obter e atualizar o conhecimento sobre uma temática específica em curto espaço de tempo (Freire, Silva, Carvalho \& Ferreira, 2020).

A busca pelos artigos foi realizada no período de agosto a setembro de 2021. A pesquisa foi realizada por meio da busca de artigos nas bases de dados virtuais especializadas na área de saúde tais como: Scientific Electronic Library Online (Scielo), por meio da Biblioteca Virtual em Saúde (BVS) e Literatura Latino Americana e do Caribe em Ciências da Saúde (LILACS).

Como critérios de inclusão foi-se utilizado: os artigos de língua portuguesa, que abrangessem o tema abordado, disponíveis nas bases de dados na íntegra, publicados no período compreendido entre 2011 a 2021, utilizando os descritores: HIV/AIDS; Prevenção; Jovens; vulnerabilidade; prevenção cominada.

Foram eliminados todos os artigos que não abordavam especificamente a temática proposta, as revisões de literatura, teses, e os trabalhos que não atenderam ao recorte temporal estabelecido. Foram revisados os títulos e os resumos dos artigos identificados nas bases de dados, aqueles que abordavam a temática do artigo foram inclusos.

Para análise do material utilizou-se da técnica da análise temática, a partir de Freire et al., (2020) baseada nos seguintes passos: leitura e familiarização com achados; geração dos códigos iniciais-expressões ou palavras consideradas interessantes ao objetivo da pesquisa; agrupamento destes códigos em eixos temáticos; a revisão dos temas e a geração do mapa temático de análise; e geração do artigo. Foram construídos os seguintes temas: Vulnerabilidades do público jovem ao HIV e Práticas educativas e métodos voltados ao público jovem para prevenção ao HIV.

\section{Resultados e Discussão}

Posteriormente a aplicação das estratégias de busca, foram encontradas 61 publicações científicas, destes, 51 foram excluídos, sendo 23 por não terem o público jovem como foco do estudo, 8 por só está disponível o resumo, 4 por não ter disponibilização gratuita. Assim, 16 passaram para próxima etapa de seleção, sendo realizada a leitura de seus resumos, 
restando 10 artigos para compor esta revisão bibliográfica. A Figura 1, apresenta a estratégia de busca utilizada para obtenção dos artigos.

Figura 1. Estratégia de busca utilizada para obtenção dos artigos.

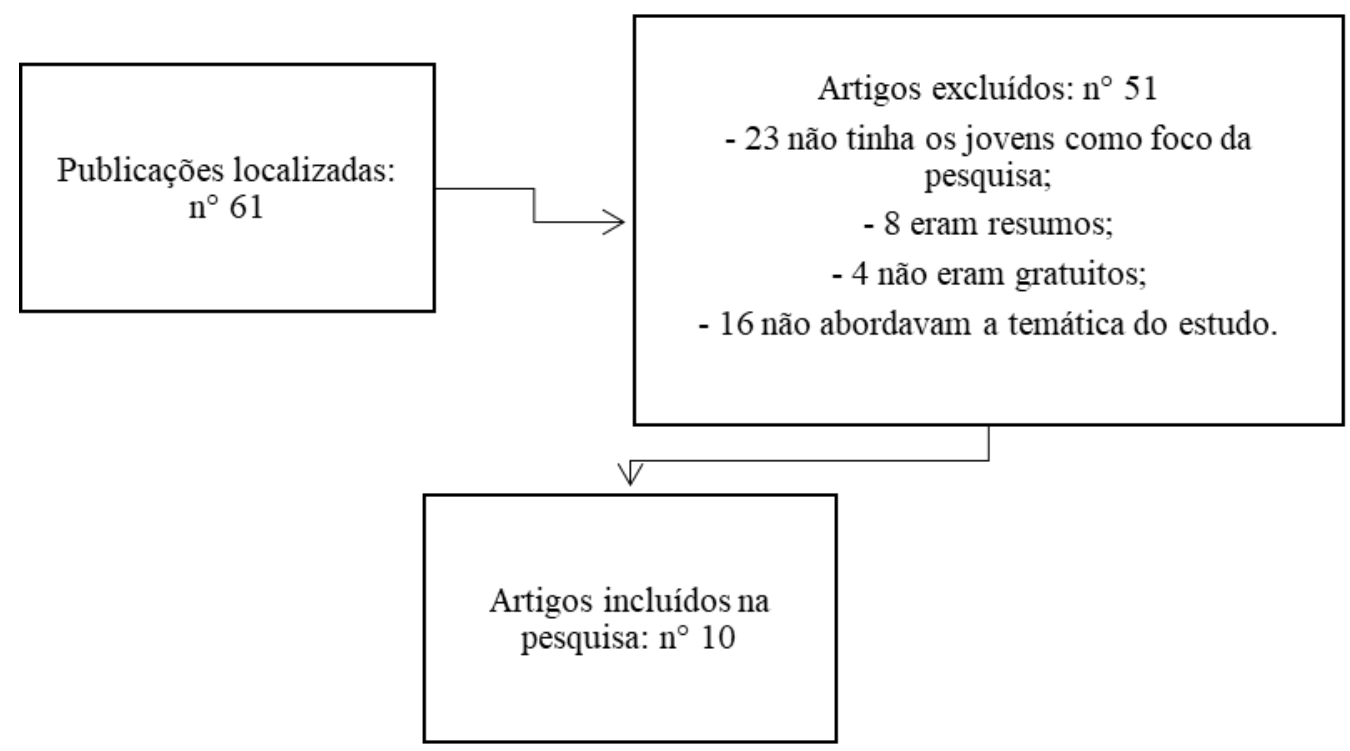

Fonte: Autores.

Para melhor precisão dos dados dos artigos, elaborou-se uma tabela contendo as seguintes informações: título, autores, ano de publicação, tipo de estudo e objetivo. Estando os 10 artigos dispostos na Tabela 1.

Tabela 1. Classificação metodológica dos artigos selecionados para revisão narrativa sobre dificuldades de prevenção ao vírus HIV na população jovem e a importância da prevenção combinada. (2011-2021).

\begin{tabular}{|c|c|c|c|c|}
\hline $\begin{array}{c}\text { Ano de } \\
\text { Publicação }\end{array}$ & Título & Autores & Tipo de estudo & Objetivo \\
\hline 2013 & $\begin{array}{l}\text { Conhecimento e } \\
\text { comportamento sexual dos } \\
\text { universitários diante a } \\
\text { vulnerabilidade ao hiv/aids }\end{array}$ & $\begin{array}{l}\text { Oliveira, } \\
\text { Araújo, } \\
\text { Alchieric \& } \\
\text { Medeiros, } \\
\text { (2013). }\end{array}$ & $\begin{array}{c}\text { Descritivo, } \\
\text { exploratório } \\
\text { fundamentado na } \\
\text { abordagem } \\
\text { quantitativa. }\end{array}$ & $\begin{array}{l}\text { Verificar o conhecimento } \\
\text { sobre o assunto e sua } \\
\text { possível relação com o } \\
\text { cuidado diante do } \\
\text { comportamento sexual dos } \\
\text { jovens universitários dos } \\
\text { cursos de graduação de uma } \\
\text { universidade pública do } \\
\text { nordeste brasileiro e as } \\
\text { situações de vulnerabilidade } \\
\text { de contaminação por HIV. }\end{array}$ \\
\hline \multirow[t]{2}{*}{2013} & \multirow[t]{2}{*}{$\begin{array}{c}\text { Fatores associados à } \\
\text { infecção pelo HIV/AIDS } \\
\text { entre adolescentes e } \\
\text { adultos jovens } \\
\text { matriculados em Centro de } \\
\text { Testagem e } \\
\text { Aconselhamento no Estado } \\
\text { da Bahia, Brasil }\end{array}$} & Pereira et al & $\begin{array}{l}\text { Estudo analítico } \\
\text { com delineamento } \\
\text { transversa }\end{array}$ & $\begin{array}{c}\text { Investigar os fatores } \\
\text { associados à } \\
\text { soropositividade ao HIV } \\
\text { entre jovens matriculados } \\
\text { no Centro de Testagem e } \\
\text { Aconselhamento (CTA) do } \\
\text { Centro de Referência }\end{array}$ \\
\hline & & & & $\begin{array}{c}\text { Municipal (CRM) de } \\
\text { DST/HIV/AIDS de Feira de } \\
\text { Santana, Bahia, Brasil }\end{array}$ \\
\hline 2014 & $\begin{array}{l}\text { Comportamentos e práticas } \\
\text { sexuais de homens que } \\
\text { fazem sexo com homens }\end{array}$ & Lima et al & $\begin{array}{c}\text { Estudo transversal, } \\
\text { exploratório } \\
\text { descritivo }\end{array}$ & $\begin{array}{l}\text { Identificar comportamentos } \\
\text { e práticas sexuais de } \\
\text { homens que fazem sexo }\end{array}$ \\
\hline
\end{tabular}




\begin{tabular}{|c|c|c|c|c|}
\hline & & & & $\begin{array}{c}\text { com homens no contexto da } \\
\text { vulnerabilidade ao } \\
\text { HIV/AIDS }\end{array}$ \\
\hline 2016 & $\begin{array}{l}\text { Fatores contribuintes da } \\
\text { vulnerabilidade individual } \\
\text { dos jovens ao hiv }\end{array}$ & Rodrigues et al & $\begin{array}{l}\text { Inquérito } \\
\text { populacional }\end{array}$ & $\begin{array}{c}\text { Definir os fatores } \\
\text { contribuintes da } \\
\text { vulnerabilidade individual } \\
\text { ao HIV entre os jovens }\end{array}$ \\
\hline 2016 & $\begin{array}{c}\text { Prática educativa com } \\
\text { jovens usuários de crack } \\
\text { visando a prevenção do } \\
\text { HIV/AIDS }\end{array}$ & $\begin{array}{l}\text { Pinto, Bezerra, } \\
\text { Luna, Lira \& } \\
\text { Pinheiro }\end{array}$ & $\begin{array}{c}\text { Pesquisa de } \\
\text { natureza qualitativa }\end{array}$ & $\begin{array}{l}\text { Relatar a intervenção } \\
\text { educativa com jovens } \\
\text { usuários de crack visando à } \\
\text { prevenção do HIV/AIDS } \\
\text { através da metodologia de } \\
\text { Círculo de Cultura }\end{array}$ \\
\hline 2017 & $\begin{array}{l}\text { Fatores associados ao } \\
\text { baixo conhecimento sobre } \\
\text { HIV/AIDS entre homens } \\
\text { que fazem sexo com } \\
\text { homens no Brasil }\end{array}$ & $\begin{array}{l}\text { Gomes, } \\
\text { Ceccato, } \\
\text { Sansigolo \& } \\
\text { Guimarães }\end{array}$ & Estudo transversal & $\begin{array}{l}\text { Analisar os fatores de } \\
\text { vulnerabilidade social, } \\
\text { individual e programática } \\
\text { associados ao baixo } \\
\text { conhecimento em } \\
\text { HIV/AIDS entre homens } \\
\text { que fazem sexo com } \\
\text { homens (HSH). }\end{array}$ \\
\hline 2017 & $\begin{array}{c}\text { Fatores determinantes de } \\
\text { conhecimentos, atitudes e } \\
\text { práticas em DST/Aids e } \\
\text { hepatites virais, entre } \\
\text { jovens de } 18 \text { a } 29 \text { anos, no } \\
\text { Brasil }\end{array}$ & Fontes et al & Estudo qualitativo & $\begin{array}{c}\text { Avaliar a vulnerabilidade } \\
\text { dos jovens brasileiros às } \\
\text { DSTs/Hiv Aids e Hepatites } \\
\text { Virais. }\end{array}$ \\
\hline 2019 & $\begin{array}{l}\text { Oficinas de prevenção } \\
\text { combinada ao HIV/Aids na } \\
\text { região do Partenon/Lomba } \\
\text { do Pinheiro em Porto } \\
\text { Alegre }\end{array}$ & $\begin{array}{l}\text { Mello, Botelho, } \\
\text { Maia \& Pinto }\end{array}$ & $\begin{array}{l}\text { Formato de roda } \\
\text { viva, com dinâmicas } \\
\text { coerentes }\end{array}$ & $\begin{array}{l}\text { Reconhecer que nenhuma } \\
\text { intervenção de prevenção } \\
\text { isolada é suficiente para } \\
\text { reduzir novas infecções e } \\
\text { que diferentes fatores de } \\
\text { risco de exposição, } \\
\text { transmissão e infeção } \\
\text { operam de forma dinâmica } \\
\text { em diferentes condições } \\
\text { sociais, econômicas, } \\
\text { culturais e políticas }\end{array}$ \\
\hline 2019 & $\begin{array}{c}\text { Fatores associados ao uso } \\
\text { de preservativo em jovens } \\
\text { - inquérito de base } \\
\text { populacional }\end{array}$ & Gutierrez et al & $\begin{array}{l}\text { Inquérito de base } \\
\text { populacional }\end{array}$ & $\begin{array}{l}\text { Identificar os fatores } \\
\text { associados ao uso de } \\
\text { preservativo na última } \\
\text { relação sexual }\end{array}$ \\
\hline 2021 & $\begin{array}{l}\text { O Teatro como estratégia } \\
\text { de engajamento de jovens } \\
\text { no enfrentamento da Aids }\end{array}$ & $\begin{array}{l}\text { Almeida, } \\
\text { Bento, Jardim } \\
\text { \& Ramalho }\end{array}$ & $\begin{array}{l}\text { Estudo prático e } \\
\text { teórico }\end{array}$ & $\begin{array}{c}\text { Compreender o potencial da } \\
\text { peça para engajar jovens no } \\
\text { debate sobre HIV/Aids e a } \\
\text { relação desses jovens com o } \\
\text { tema, visando contribuir } \\
\text { para o esforço empreendido } \\
\text { pela Fiocruz e pelo país na } \\
\text { tentativa de controlar a } \\
\text { epidemia. }\end{array}$ \\
\hline
\end{tabular}

Fonte: Autores.

\subsection{Vulnerabilidades do público jovem ao hiv}

Oliveira et al., (2013) realizaram um estudo descritivo, exploratório fundamentado na abordagem quantitativa, realizado no Campus Avançado Professora Maria Elisa de Albuquerque Maia, da Universidade do Estado do Rio Grande do Norte. Contou com a participação de 430 alunos com faixa etária compreendida entre 20 a 24 anos 11 meses e 29 dias e os dados foram obtidos por meio de questionário.

O Objetivo de Oliveira et al., (2019) foi a verificação do nível de conhecimento sobre o HIV e as formas de transmissão e prevenção; caracterização do comportamento sexual nas relações afetivas dos jovens universitários e as situações 
de vulnerabilidade que se colocam diante do contágio pelo HIV; e identificação dos aspectos psicossociais que influenciam a adoção ou não de métodos de barreira à transmissão do HIV por via sexual.

O estudo demonstrou que o conhecimento sobre as formas de prevenção e infecção do HIV, ainda que importante, não se mostra fator determinante na adoção do uso da camisinha nas relações sexuais dos universitários. Uma vez que que 90,7\% reconheceram o sexo sem camisinha como principal forma de infecção pelo HIV, e 100\% elegeram o sexo protegido como forma mais eficaz, mas destes apenas $0,5 \%$ foram específicos quanto ao uso de camisinha no sexo oral, $0,2 \%$ sobre o uso de camisinha no sexo anal e $0,2 \%$ sobre o uso do preservativo no sexo vaginal. Ter somente um parceiro sexual foi citado por 2,3\%; abstinência sexual por 0,7\%, e escolha adequada e/ou conhecimento dos parceiros por 4,2\% (Oliveira et al., 2019).

Os entrevistados mostraram que detém grande conhecimento sobre o HIV, mas mesmo com todo conhecimento, em algum momento apresentaram comportamento sexual que os colocaram em situação de vulnerabilidade ao HIV pelo não uso da camisinha, dos participantes que já tinham tido uma relação sexual completa $(n=286), 71 \%$ fizeram sexo sem camisinha. O não uso da camisinha foi justificado por características de cada relacionamento estabelecido com o parceiro ou parceira, o nível de envolvimento nas relações afetivo-amorosas, bem como a fatores inerentes à construção da sexualidade de cada indivíduo (Oliveira et al., 2019).

Quando questionados sobre o conhecimento de seu estado sorológico, $(84,7 \%)$ dos participantes nunca tinham feito o teste sorológico anti-HIV para detecção de anticorpos ao vírus. Mesmo aqueles que após terem uma relação sexual sem o uso da camisinha se submetam ao teste (12,3\%). Assim Oliveira et al., (2019) verificaram que o conhecimento sobre o problema não anula a vulnerabilidade desses participantes à contaminação pelo HIV.

No estudo de Lima et al., (2014) o objetivo da pesquisa era a identificação dos comportamentos e as práticas sexuais de HSH, a fim de reconhecer o contexto de vulnerabilidade em que a referida população está inserida, bem como identificação do perfil social e sexual dos HSH.

Tratou-se de um estudo transversal do tipo exploratório descritivo, realizado em uma boate localizada no centro de Fortaleza no Ceará, sendo esta considerada como um dos principais locais de sociabilidade gay da cidade. A amostra constituiu $189 \mathrm{HSH}$, destes a maioria $(96,3 \%)$ relataram a realização de sexo oral e $(97,8 \%)$ dos sujeitos referiram à prática do sexo anal. Foi encontrado uma elevada prevalência da prática do sexo anal desprotegido na amostra estudada, pois (12,7\%) dos entrevistados disseram não usar proteção e (6,9\%) assumiram a utilização da proteção "às vezes" (Lima et al., 2014).

Um dado importante notado pelo mesmo autor, foi que 73,5\% dos entrevistados já realizaram de teste anti-HIV, o que indica uma suposta relação com a prática recorrente de comportamentos de risco, que provocaria medo de ter contraído o HIV e que levaria à procura pelo teste. O que pode ser verificado quanto a frequência do uso do preservativo, que na prática do sexo oral $(47,7 \%)$ disseram nunca usar preservativo, e na pratica do sexo anal apenas $(73,5 \%)$ fazem o uso do preservativo independentemente do tipo do sexo

Gomes et al., (2017) também realizou um estudo voltado ao púbico jovem de HSH, estes, buscaram a identificação dos fatores indicadores de vulnerabilidade social, individual e programática associados ao baixo conhecimento sobre HIV/AIDS em uma amostra da população de HSH recrutados em dez cidades brasileiras. Realizaram esta busca por meio de questionário, onde foram abordados um total de 3.746 participantes.

Constaram que as variáveis indicadoras de vulnerabilidade social mostraram que a maioria dos HSH possuíam mais de oito anos de estudo $(58,3 \%)$, pele negra $(74 \%)$, se declaravam solteiros $(84,8 \%)$, possuíam trabalho $(66,5 \%)$, com renda individual maior que $\mathrm{R} \$ 750,00$ (74,3\%), que não se sentiram discriminados (72,4\%) e não sofreram agressão verbal $(56,6 \%)$ nos últimos 12 meses devido à sua orientação sexual, e que já tinham falado sobre uma orientação sexual para alguém do grupo familiar e/ou social (74\%) (Gomes et al., 2017). 
Quanto às variáveis indicadoras de vulnerabilidade individual, os entrevistados referiram a primeira relação sexual com mais de 14 anos $(53,4 \%)$. Cerca de (32\%) relataram fazer uso inconsistente de preservativos em relação anal receptiva nos últimos seis meses, e $(44,3 \%)$ relataram já ter se esquecido de usar preservativos com o uso de álcool e drogas. Uma proporção considerável relatou o consumo de bebidas alcoólicas duas ou mais vezes por semana (63,7\%) e terem relação sexual após a ingestão (61,3\%) (Gomes et al., 2017).

Já as variáveis indicadoras de vulnerabilidade programática, destacou-se a alta proporção de HSH que nunca realizaram a testagem para o HIV $(49,5 \%)$ e para a sífilis $(75 \%)$. Com relação aos insumos, $(85,1 \%)$ nunca tinham recebido gel lubrificante nos últimos 12 meses e $(44,1 \%)$ evidenciaram nunca terem recebido preservativos gratuitos, e os que receberam informaram que foram insuficientes. Estes resultados permitiram a Gomes et al., (2017) a constatação tanto pela análise univariada, como por análises multivariadas intermediárias, que as formas de transmissão da infecção entre a população de HSH têm associação estatisticamente significativa com o baixo conhecimento.

Com o objetivo de identificar os fatores associados ao uso de preservativo na última relação sexual entre jovens de 15 a 24 anos residentes no Município de São Paulo, Gutierrez et al., (2019), realizou um estudo de corte transversal que integra a Pesquisa de Conhecimentos, Atitudes e Práticas na população de São Paulo. Foram entrevistados 4.318 indivíduos residentes na região urbana da cidade.

Quanto aos fatores associados ao uso de preservativo na última relação sexual entre as mulheres jovens, constaram que os fatores relacionados positivamente com o uso de preservativo na última relação sexual foram: nunca ter sido casada; ter feito uso de preservativo na primeira relação sexual; ter tido parceria sexual casual no último ano; primeira relação sexual após os 15 anos de idade; e pegar preservativo de graça. No entanto, idade, parceria fixa no último ano e já ter feito o teste anti-HIV foram associados negativamente com o uso de preservativo na última relação sexual (Gutierrez et al., 2019).

Já no público masculino, os fatores associados ao uso de preservativo na última relação sexual foram: ser solteiro; ter usado preservativo na primeira relação sexual; ter tido parceria casual no último ano; ter tido relação sexual com pessoa do mesmo sexo; e ter obtido preservativo gratuitamente. Quanto os fatores negativos, observou-se a idade, ou seja, os mais novos usaram mais o preservativo. Verificaram também uma baixa frequência do uso de preservativos entre jovens, tanto na primeira como na última relação sexual, sendo de $(60,7 \%)$ de uso na primeira relação e $(52,4 \%)$ na última relação, sem diferença entre homens e mulheres, apesar do alto grau de conhecimento sobre a importância do uso de preservativo para a prevenção de IST e HIV (Gutierrez et al., (2019). Sendo este último também constatado por Oliveira et al., (2013).

Já Pereira et al., (2013) investigou os fatores associados à soropositividade ao HIV entre jovens matriculados no Centro de Testagem e Aconselhamento (CTA) do Centro de Referência Municipal (CRM) de DST/HIV/AIDS de Feira de Santana, Bahia, Brasil. Tiveram por amostra 558 pessoas, sendo 321 do sexo masculino e 237 do sexo feminino. Verificaram que há uma relação entre a infecção pelo HIV e o uso de outras drogas e orientação homossexual/bissexual entre homens, e para as mulheres a relação está no uso de álcool e outras drogas e união estável, e o parceiro usuário de drogas e/ou portador de HIV e DST para ambos os sexos.

Fontes et al., (2017), desenvolveu sua pesquisa voltada a apresentar qual a vulnerabilidade de jovens com relação à transmissão de DST/AIDS por via sexual. Para isso foram ouvidos 1.208 jovens entre 18 e 29 anos, em 15 Estados e no Distrito Federal. Como meio de obtenção dos dados elaboraram uma escala de Conhecimentos, Atitudes e Práticas especificamente para HIV/AIDS, IST's e Hepatites Virais a qual envolveu 17 conhecimentos, 10 atitudes e 08 práticas, totalizando 35 variáveis.

Apuraram que com relação aos conhecimentos, (40\%) dos entrevistados não consideram o uso de camisinha um método muito eficaz de prevenção de DST/Aids ou gravidez, (24\%) acreditavam que se pode adquirir HIV/Aids pela saliva, $(15 \%)$ dos jovens acreditava que malária, dengue, hanseníase ou tuberculose são IST’s. Relacionado as atitudes (40\%) dos 
entrevistados consideravam que quando o relacionamento é estável não é necessário o uso da camisinha, (23,3\%) consideravam que a fidelidade a um parceiro (a) não diminui as chances de se contrair IST's, e aproximadamente (20\%) dos jovens se sentiriam insultados ou com raiva se o (a) seu (sua) parceiro (a) quisesse fazer uso de preservativo durante o ato sexual. Quanto as práticas, $(36,1 \%)$ não utilizaram preservativo na última vez que tiveram relações sexuais, e somente $9,4 \%$ foram a centro de saúde nos últimos 12 meses para obter informações ou tratamento para IST's. Assim Fontes et al., (2017) constaram que a vulnerabilidade dos jovens brasileiros continua alta, uma vez que a percepção de risco é significativamente baixa, pois este público ainda é muito carente de informação.

Embasando na ideia de que parte da vulnerabilidade dos jovens depende também de fatores cognitivos e comportamentais ligados à voluntariedade dos sujeitos, Rodrigues et al., (2016), buscou investigar quais os contribuintes da vulnerabilidade individual ao HIV entre os jovens nos contextos em que eles interagem. Para isso realizaram estudo descritivo, tipo inquérito, com jovens das escolas públicas municipais de João Pessoa - PB.

Quando avaliadas as variáveis sociodemográficas, observaram que ser do sexo masculino, pardo, solteiro (a), desempregado (a), possuir renda familiar de até dois salários, ter mais três dependentes, não receber tipo de auxílio financeiro, ser católico e apresentar interesse sexual por pessoa do sexo oposto mostraram-se como determinantes da vulnerabilidade individual dos jovens ao HIV. Já quando estudado a iniciação da vida sexual e não uso do preservativo durante as relações sexuais, observaram que o início precoce, associado ao não uso do preservativo se mostraram como um fator de influência para o aumento da vulnerabilidade individual dos jovens ao HIV (rodrigues et al., 2016).

\subsection{Práticas educativas e métodos voltados ao público jovem para prevenção ao hiv}

A forma lúdica de ensinar, proporciona ações dialógicas, possibilitando o surgimento do novo e à reflexão fundamentada na criatividade, a partir disso, o sujeito torna-se, então, o agente transformador. O aprendizado significativo procura novas metodologias, para assim desenvolver uma base consolidada de conhecimentos e atitudes, de forma ativa e autônoma e, também, possibilitar a interação dialógica (Costa et al., 2020).

Pinto et al., (2016) realizaram uma pesquisa de natureza qualitativa, baseada na metodologia de Círculo de Cultura. Este é um espaço de trabalho, pesquisa, dinâmicas e vivências que proporcionam a elaboração coletiva do conhecimento e a reflexão crítica do meio em que o sujeito está inserido.

Os sujeitos, participantes da pesquisa de Pinto et al., (2016) foram: sexo masculino, usuários das unidades de tratamento/ambulatório para dependentes químicos e que referiram ter feito uso de crack, e que fossem da faixa etária de 15 e 24 anos de idade. No total tiveram 10 participantes, destes um tinha o fundamental incompleto, dois completaram o ensino fundamental, cinco adolescentes tinham o ensino médio incompleto e apenas dois cursaram o ensino médio completo. Dois eram casados, dois conviviam conjugalmente e seis se declararam solteiros.

Para abordagem desse público foi realizado visitas à comunidade terapêutica e encontro educativo guiado pelos princípios do Círculo de Cultura. Ao todo, foram quatro visitas realizadas com duração de 1 hora, todas no turno da manhã. O encontro educativo teve duração de duas horas e meia, ocorreu nas dependências da comunidade terapêutica. Pinto et al., (2016) observaram que a problematização proporcionada pelo Círculo de Cultura permitiu aos jovens expor suas vulnerabilidades ao HIV/AIDS, visto que os conhecimentos prévios destes jovens acerca do HIV/AIDS eram poucos e com predominância de mitos.

Já, com a discussão grupal, os jovens reconhecerem que o compartilhamento de canudos e cachimbos para o uso da cocaína/crack e a perda da consciência favoreciam ao não uso do preservativo durante as relações sexuais e à multiplicidade de parceiros, aumentando, assim, o risco de infecção pelo HIV/AIDS (Pinto et al., 2016). 
O teatro foi a estratégia de comunicação sobre HIV/Aids que Almeida et al., (2021) utilizaram para a entender se e como o espetáculo teatral é capaz de envolver emocionalmente e cognitivamente os espectadores de modo que se apropriem dos conhecimentos em jogo e participem ativamente do debate sobre HIV/Aids.

O título do espetáculo apresentado foi "O rapaz da rabeca e a moça Rebeca". Almeida et al., (2021) consideraram a participação de 220 jovens que se enquadraram em seus critérios de inclusão. Estes foram convidados a responderem a um questionário, o qual relataram que a escolha do tema da peça, abordando Aids, preconceito e formas de prevenção da doença, foi considerada um dos grandes acertos do espetáculo, por se tratar de um "assunto sério", "real", "atual" e "pouco falado". Outros pontos positivos destacados foram a utilização de música, dança e humor, o enredo e o desempenho dos atores. Grande parte dos entrevistados relataram que as informações mais relevantes absorvidas da peça, foram os meios de prevenção, de desconstrução do tabu em torno da sexualidade e do HIV/aids e a de que é preciso acabar com o estigma associado à doença.

Almeida et al., (2021) puderam constatar que os jovens carecem de informações básicas sobre o vírus e a doença, pois não souberam responder alguns questionamentos sobre os meios de contaminação, e que esta falta de conhecimento do assunto está relacionada aos tabus que envolvem esse assunto. Por fim concluíram que este meio de abordagem, unindo Saúde e Teatro em uma atividade de divulgação científica bem-sucedida, pois se teve boa adesão do público alvo, com participação e envolvimento ativo do mesmo.

Outro método de abordagem do público jovem foi utilizado por Mello et al., (2019), estes realizaram oficinas de prevenção, promoção e educação em saúde com foco na estratégia da Prevenção Combinada. Para a abordagem metodológica, optaram por utilizar o formato de roda viva, com dinâmicas coerentes com o propósito de debater e desenvolver o tema de forma participativa, de modo que cada participante se sentisse à vontade para falar sobre o que sabia, ou não, a respeito do assunto.

Cada oficina teve o limite de 20 pessoas para que assim, todos pudessem participar. Para o desenvolvimento das discussões foi utilizado a "Mandala da Prevenção Combinada", figura elaborada pelo Ministério da Saúde e representativa de uma ideia de movimento e complementariedade entre as diferentes estratégias de prevenção. Com a figura da Mandala foi sugerido um jogo onde cada participante era estimulado a comentar a respeito de uma das estratégias presentes na figura e, a partir disso, incentivava-se a participação e o diálogo entre todos, explorando a temática da prevenção combinada em sua interface com estigma, preconceito e relações de gênero (Mello et al., 2019)

Outra metodologia trabalhada, foi a elaboração, em pequenos grupos, de estudos de caso, estes podiam ser fundamentados em experiências reais ou elaborados a partir de situações inventadas. Para a apresentação dos mesmos, foram utilizados recursos lúdicos tais como leitura compartilhada, teatro e produção de vídeo. Na ocasião também foram feitas demonstrações do uso do preservativo masculino e feminino onde estas foram distribuídos juntamente com gel lubrificante e materiais informativos sobre a temática, guia de advocacy do Movimento Nacional das Cidadãs Posithivas, com conteúdo diversificado, em especial das questões estruturais da epidemia do HIV/Aids e materiais da Estratégia de Prevenção Combinada com informações de acesso aos serviços que ofertam a testagem, a profilaxia Pré Exposição (PrEP) e Profilaxia Pós Exposição (PEP) (Mello et al., 2019).

Os participantes das oficinas elaboradas por Mello et al., (2019) demonstraram interesse nas discussões e sensibilidade para as temáticas debatidas, especialmente as de ordem social. Durante os debates foram apontadas as dificuldades enfrentadas no que se refere à escuta qualificada, empatia e criação do vínculo entre usuário e serviços.

\section{Considerações Finais}

Frente as publicações exploradas nesta revisão, observou-se que a maiores dificuldades de prevenção vírus HIV na população jovem está relacionada as vulnerabilidades que este grupo está exposta. Foi possível verificar que grande parte dos 
autores relataram que os jovens têm a camisinha como sendo a principal barreira de prevenção, mais que mesmo sabendo desta informação ainda existem aqueles que não fazem o uso, por não acharem necessário ou por conhecerem e confiarem nos parceiros, ou por não considerarem seu uso relevante na prática do sexo oral por exemplo. Isso mostra que cada um possui suas próprias convicções apesar de conhecerem a forma certa de agir.

Já as práticas educativas, todas as apresentadas na revisão se mostraram eficientes, uma vez que métodos inovadores, buscando chamar a atenção do público alvo foram bem aceitos e obtiveram participação ativa dos envolvidos.

Por fim, foi possível observar, que a maior parte das produções publicadas no recorte temporal proposto por esta revisão, estão voltadas a apresentar as vulnerabilidades do público jovem ao HIV, e que destacam a importância das políticas públicas mais centradas nesse público. Apenas uma publicação é voltada a prevenção combinada, que mostra que essa área ainda é pouco explorada apesar de ser um assunto tão recorrente.

Para um melhor esclarecimento ao tema, sugere-se que outros estudos procurem identificar os fatores dificultantes da adesão do púbico aos métodos preventivos ao HIV, buscando esclarecer as dificuldades enfrentadas por esse público quanto a criação de vínculo com o sistema de saúde e os programas vigentes no SUS. Sugere-se também que seja avaliado os benefícios de se trabalhar a prevenção combinada com este púbico, para que assim torne-se evidente que sua utilização é eficiente na prevenção a contaminação pelo HIV.

\section{Referências}

Almeida, C., Bento, L., Jardim, G., Ramalho, M., Amorim, L., \& Folino, C. H. (2021). O Teatro como estratégia de engajamento de jovens no enfrentamento da Aids. Interface-Comunicação, Saúde, Educação, (25), e200402. https://doi.org/10.1590/interface.200402

Brasil. Ministério da Saúde. Secretaria de Vigilância em Saúde. Departamento de Doenças de Condições Crônicas e Infecções Sexualmente Transmissíveis DCCI. Boletim Epidemiológico. (2020). https://www.gov.br/saude/pt-br/assuntos/media/pdf/2020/dezembro/01/boletim-hiv_aids-2020-internet.pdf

Brasil. Ministério da Saúde. Secretaria de Vigilância em Saúde. Departamento de Vigilância, Prevenção e Controle das Infecções Sexualmente Transmissíveis, do HIV/Aids e das Hepatites Virais. Diretrizes para a organização dos serviços de saúde que ofertam a Profi laxia Pré-Exposição Sexual ao HIV (PrEP) no Sistema Único de Saúde / Ministério da Saúde, Secretaria de Vigilância em Saúde. Brasília: Ministério da Saúde, 2017. file:///C:/Users/u100928 0/Do wnloads/diretrizes_prep_11_2017_web.pdf

Cordeiro, L. I., Lopes, T. D. O., Lira, L. E. D. A., Feitoza, S. M. D. S., Bessa, M. E. P., Pereira, M. L. D., Rodrigues, A. S, \& Souza, A. R. D. (2017). Validação de cartilha educativa para prevenção de HIV/Aids em idosos. Revista Brasileira de Enfermagem, 70, 775-782. https://doi.org/10.1590/0034-71672017-0145

Costa, P. H. A. D., Mota, D. C. B., Paiva, F. S. D., \& Ronzani, T. M. (2015). Desatando a trama das redes assistenciais sobre drogas: uma revisão narrativa da literatura. Ciência \& Saúde Coletiva, (20), 395-406. https://doi.org/10.1590/1413-81232015202.20682013

Costa, T. R. M., Santos, S. P. H., Correia, R. S., Cruz, V. T., Paula, W. C., Souza, J. L., Lima, J. C. F., Pereira, S. A., Cavalcante, S. S. J., \& dos Santos, K. R. (2020). A relevância da inserção do lúdico para a construção do processo ensino-aprendizado na educação para a saúde. Research, Society and Development, 9(9), e362997296-e362997296. http://dx.doi.org/10.33448/rsd-v9i9.7296

Dartora, W. J., Ânflor, E. P, \& Silveira, L. R. P. (2017). Prevalência do HIV no Brasil 2005-2015: dados do Sistema Único de Saúde. Revista Cuidarte, 8(3), 1919-1928. http://dx.doi.org/10.15649/cuidarte.v8i3.462

Freire, O. M. C., Carvalho, S. C. C., Lemos, A. M. A. C., Silva, L. B., \& Ferreira, S. M. S. (2020). O HIV/Aids na vida de mulheres mães: uma revisão narrativa da literatura. Diversitas Journal, 5(4), 2921-2929. https://doi.org/10.17648/diversitas-journal-v5i4-1084

Fontes, M. B., Crivelaro, R. C., Scartezini, A. M., Lima, D. D., Garcia, A. D. A., \& Fujioka, R. T. (2017). Fatores determinantes de conhecimentos, atitudes e práticas em DST/Aids e hepatites virais, entre jovens de 18 a 29 anos, no Brasil. Ciência \& Saúde Coletiva, 22 (4), 1343-1352. https://doi.org/10.1590/141381232017224.12852015

Gomes, R. R. D. F. M., Ceccato, M. D. G. B., Kerr, L. R. F. S., \& Guimarães, M. D. C. (2017). Fatores associados ao baixo conhecimento sobre HIV/AIDS entre homens que fazem sexo com homens no Brasil. Cadernos de Saúde Pública, 33 (10), e00125515. https://doi.org/10.1590/0102-311X00125515

Gutierrez, E. B., Pinto, V. M., Basso, C. R., Spiassi, A. L., Lopes, M. E. D. B. R., \& Barros, C. R. D. S. (2019). Fatores associados ao uso de preservativoem jovens-inquérito de base populacional. Revista Brasileira de Epidemiologia, (22), e190034. https://doi.org/10.1590/1980-549720190034

Lima, D. J. M., Paula, P. F. D., Lessa, P. R. A., Moraes, M. L. C. D., Cunha, D. D. F. F., \& Pinheiro, A. K. B. (2014). Comportamentos e práticas sexuais de homens que fazem sexo com homens. Revista Brasileira de Enfermagem, (67), 886-890. https://doi.org/10.1590/0034-7167.2014670604

Mello, V. R. C., Aloia, S. A. V., Rangel, R. D., \& Travassos, G. N. (2019). \# NosOtras-Oficinas de prevenção combinada ao HIV/Aids na região do Partenon/Lomba do Pinheiro em Porto Alegre. Revista Eletrônica Científica Da UERGS, 5(2), 182-190. https://doi.org/10.21674/2448-0479.52.182-190 
Research, Society and Development, v. 10, n. 13, e360101321440, 2021

(CC BY 4.0) | ISSN 2525-3409 | DOI: http://dx.doi.org/10.33448/rsd-v10i13.21440

Monteiro, R. S. D. M., Feijão, A. R., Barreto, V. P., Silva, B. C. O. D., Neco, K. K. D. S, \& Aquino, A. R. G. D. (2019). Ações educativas sobre prevenção de HIV/AIDS entre adolescentes em escolas. Enfermería Actual de Costa Rica, (37), 206-222. http://dx.doi.org/10.15517/revenf.v0ino.37.36749

Oliveira, J. G., Araújo, J. L., Alchieri, J. C., Medeiros, P. A. K. A., Nascimento, E. G. C., \& Vasconcelos, R. B. (2013). Conhecimento e comportamento sexual dos universitários diante a vulnerabilidade ao HIV/AIDS. Revista Baiana de Saúde Pública, 37(3), 702-724. http://files.bvs.br/upload/S/01000233/2013/v37n3/a4470.pdf

Paiva, V., Antunes, M. C., \& Sanchez, M. N. (2019). O direito à prevenção da Aids em tempos de retrocesso: religiosidade e sexualidade na escola. InterfaceComunicação, Saúde, Educação, (24), e180625. https://doi.org/10.1590/Interface.180625

Pereira, B. D. S., Costa, M. C. O., Amaral, M. T. R., Santana, H. C. D., Silva, C. A. L. D., \& Sampaio, V. S. (2014). Fatores associados à infecção pelo HIV/AIDS entre adolescentes e adultos jovens matriculados em Centro de Testagem e Aconselhamento no Estado da Bahia, Brasil. Ciência \& Saúde Coletiva, 19, 747-758. https://doi.org/10.1590/1413-81232014193.16042013\%20\%20

Rodrigues, J. A., Silva, L. H. F. D., Albuquerque, S. G. E. D., Nogueira, J. D. A., Anjos, U. U. D., \& Nascimento, J. A. D. (2016). Fatores contribuintes da vulnerabilidade individual dos jovens ao HIV. Revista brasileira de ciências da saúde, 20(2), 141-148. https://periodicos.ufpb.br/ojs/index.php/rbcs/article/view/16073.

Pinto, A. C. S., Beserra, E. P., Luna, I. T., Bezerra, L. L. D. A. L., \& Pinheiro, P. N. D. C. (2016). Prática educativa com jovens usuários de crack visando a prevenção do HIV/AIDS. Escola Anna Nery, 20(3) e20160066. https://doi.org/10.5935/1414-8145.20160066

Vilares, L. M. C. B. C., Casseb, J. S. D. R., Gascon, M. R. P., \& Fonseca, L. A. M. (2018). Características de personalidade e adesão ao tratamento em pacientes jovens portadores de HIV. Revista da SBPH, 21(1), 06-35. http://pepsic.bvsalud.org/pdf/rsbph/v21n1/v21n1a02.pdf 